\title{
Proinsulin autoantibodies are more closely associated with Type 1 (insulin-dependent) diabetes mellitus than insulin autoantibodies*
}

\author{
K. Böhmer ${ }^{1}$, H.Keilacker ${ }^{2}$, B. Kuglin ${ }^{1}$, A.Hübinger ${ }^{1}$, J. Bertrams ${ }^{3}$, F. A. Gries ${ }^{1}$ and H.Kolb $^{1}$ \\ ${ }^{1}$ Diabetes Research Institute at the University of Düsseldorf, Düsseldorf, ${ }^{2}$ Institute for Diabetes, Karlsburg, and \\ ${ }^{3}$ Elisabeth Hospital, Essen, FRG
}

\begin{abstract}
Summary. The disease association of autoantibodies to proinsulin and insulin was compared in patients with Type 1 (insulin-dependent) diabetes mellitus and first-degree relatives. Following the recommendation of the Fourth International Workshop on the Standardization of insulin autoantibodies, autoantibodies were determined by fluid-phase radioimmunoassay using equimolar concentrations of mono${ }^{125} \mathrm{I}$-A14-insulin or -proinsulin to detect insulin or proinsulin autoantibodies, respectively. A higher prevalence of proinsulin autoantibodies vs insulin autoantibodies was found in 97 patients with Type 1 diabetes prior to insulin treatment $(34.0 \%$ vs $22.7 \%, p<0.05)$ and in 16 islet cell antibody-positive relatives ( $43.8 \%$ vs $31.3 \%$, NS). There was only one serum positive for insulin and proinsulin autoantibodies in
\end{abstract}

110 islet cell antibody-negative first degree relatives $(0.9 \%)$. None of 88 normal sera contained proinsulin autoantibodies or insulin autoantibodies. There was a close correlation of proinsulin autoantibody and insulin autoantibody titres in individual sera $(r=0.95, p<0.01)$ due to crossreaction of all insulin autoantibodies with proinsulin. However, some proinsulin autoantibodies did not crossreact with insulin. Background binding in normal sera was lower for proinsulin autoantibodies. We conclude that proinsulin autoantibodies have a higher association to acute Type 1 diabetes than insulin autoantibodies.

Key words: Proinsulin autoantibodies, insulin autoantibodies, Type 1 (insulin-dependent) diabetes mellitus.
Autoantibodies to insulin (IAA) and to proinsulin (PAA) have been observed to occur spontaneously during the development of Type 1 (insulin-dependent) diabetes mellitus prior to the administration of insulin [1,2]. Results of the Fourth International Workshop on the Standardization of Insulin Autoantibodies have shown a close association of IAA with Type 1 diabetes, provided they are determined by a fluid phase radioimmunoassay [3].

Using a radioimmunoassay along the Standardization Workshop guidelines (Greenbaum et al., unpublished data) we have now compared the disease association of IAA with that of PAA. In addition, sera were analysed for antibodies binding only insulin or only proinsulin, i.e. antibodies not crossreacting between insulin and proinsulin.

\section{Subjects and methods}

\section{Subjects}

Blood samples were obtained from 97 patients with newly diagnosed Type 1 diabetes prior to insulin therapy, from 16 islet cell antibody (ICA)-positive. 110 islet all antibody (ICA)-negative first-degree

* Part of this work was presented at the 26th Annual Mecting of the EASD in Copenhagen, $10^{\text {th }}-13^{\text {th }}$ September 1990 relatives of Type 1 diabetic subjects and 88 healthy volunteers. Patients ( $43 \%$ female, mean age $33.4 \pm 15.8$ ) were seen at the Diabetes Research Institute during 1987-1990; all fulfilled the World Health Organisation criteria for Type 1 diabetic subjects [4]. The nondiabetic first-degree relatives $(52 \%$ female, mean age $32.6 \pm$ 14.6 years) of patients with Type 1 diabetes were randomly selected from the Duisseldorf-Essen Family Study [5]. Of the healthy blood donors $56.7 \%$ were female with a mean age of $31.7 \pm 12.9$ years.

\section{Antibody measurements}

Islet cell antibodies (ICA) were determined by immunofluorescence on cryostat sections of snap-frozen human pancreas, blood group 0 [6]. Our laboratory participates in the worldwide ICA proficiency test [7] and our sensitivity and specificity have both been rated as $100 \%$. The detection limit of ICA was 2.5 JDF-Units.

For determination of IAA we slightly modified the method of Palmer et al. [1]. Sera were acid-charcoal extracted [8] to deplete serum insulin. Subsequently $80 \mu \mathrm{l}$ were mixed with $140 \mu \mathrm{l}$ of A14mono- ${ }^{125} I$-human insulin (specific activity $2000 \mathrm{Ci} / \mathrm{mmol}$ ) diluted in assay buffer $(0.04 \mathrm{~mol} / \mathrm{l}$ phosphate buffer ( $\mathrm{pH} 7.4)$ containing $0.5 \%$ bovine serum albumin and $0.25 \%$ bovine $\gamma$-globulin) to yield $20000 \mathrm{cpm}$. A parallel sample in addition contained $1 \mu \mathrm{g}$ of unlabelled human insulin.

After vortexing, the tubes were incubated for $18 \mathrm{~h}$ at $+4^{\circ} \mathrm{C}$. Antibody- bound insulin was precipitated by adding $1.5 \mathrm{ml} 15 \%$ polyethylene glycol (PEG) prepared in $0.05 \mathrm{~mol} / \mathrm{l}$ barbital buffer 


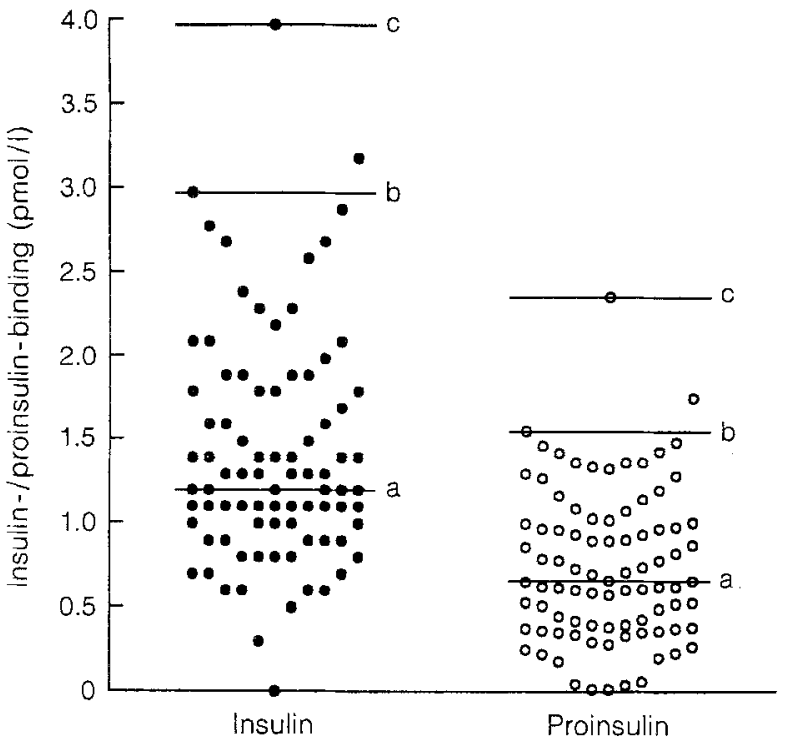

Fig. 1. Displaceable insulin and proinsulin binding in 88 normal sera. Displaceable signals observed for individual sera with insulin and proinsulin are shown. (a) median, (b) $97.5^{\text {th }}$ percentile, (c) $99^{\text {th }}$ percentile

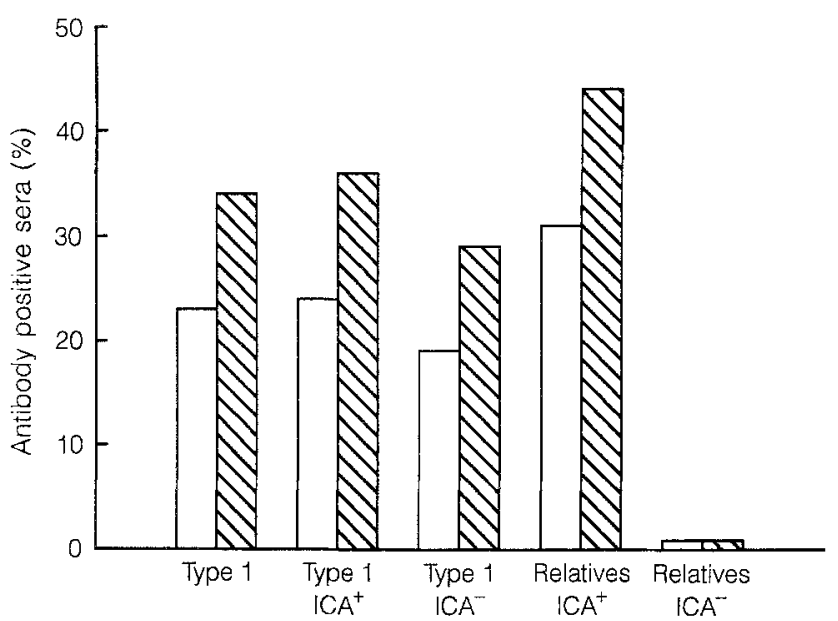

Fig.2. Prevalence of proinsulin autoantibodies (PAA) and insulin autoantibodies (IAA) in sera of patients and relatives. $\square$. IAA; \$. PAA; Type 1, patients with Type 1 (insulin-dependent) diabetes $(n=97,76$ islet cell antibody-positive, 21 islet cell antibody-negative); Relatives, islet cell antibody-positive $(n=21)$ and islet cell antibody-negative $(n=110)$ first-degree relatives of patients with Type 1 diabetes

pH 8.0 with $10 \%$ Tween 20 , afterwards mixed and centrifuged at $2500 \mathrm{~g}$ for $30 \mathrm{~min}$ at $+4{ }^{\circ} \mathrm{C}$. The pellet was washed twice with $12.5 \%$ PEG and the remaining radioactivity was counted on a gamma counter.

Antibody-bound proinsulin was determined the same way using proinsulin instead of insulin in equimolar concentrations, the specific activity was the same as for insulin. The percent specificallybound radiolabel was calculated as follows:

$\%$ bound $=\frac{\text { cpm sample }- \text { cpm sample }}{\text { inh }}$

(inh $=$ inhibited)

Human recombinant proinsulin (HPLC purified) was kindly provided by B. Frank, (Eli-Lilly Laboratories, Indianapolis, Ind, USA) human recombinant insulin was a gift from G. Seipke, (Hoechst $A G$, Frankfurt, FRG), the A14-mono- ${ }^{-125}$ I-radiolabelling was performed by R.Liebe, (Hoechst Radiochemical Laboratories, Griesheim, FRG). The isotope was highly purified by HPLC. In addition, A14mono- ${ }^{125}$ T-labelled insulin from Amersham (Braunschweig, FRG) was used. The interassay coefficients of variation were $9 \%$ at the midpoint, $11 \%$ at the bottom, $13 \%$ at the top of the binding range for both PAA and IAA. The corresponding values for intraassay binding variation were $7 \%, 9 \%, 11 \%$.

\section{Statistical analysis}

Because independency between the occurrence of IAA and PA.A in the different groups could not be assumed, non-parametric statistics have been applied. The Mann-Whitney U rank test or Wilcoxon Sign test has been used throughout. A level of $p<0.05$ was considered as significant.

\section{Results}

The median of displaceable binding of insulin by 88 normal sera was $1.190 \mathrm{pmol} / \mathrm{l}$, the minimum $0 \mathrm{pmol} / \mathrm{l}$, the maximum $3.961 \mathrm{pmol} / \mathrm{l}$, the $95 \%$ range between 0.495 and $2.968 \mathrm{pmol} / 1$, the $99^{\text {th }}$ percentile $3.961 \mathrm{pmol} / 1$. The median of proinsulin binding was $0.653 \mathrm{pmol} / 1$, the minimum $0.014 \mathrm{pmol} / \mathrm{l}$, the maximum $2.347 \mathrm{pmol} / 1$, the $95 \%$ range between 0.036 and $1.543 \mathrm{pmol} / \mathrm{l}$, the $99^{\text {th }}$ percentile $2.347 \mathrm{pmol} / \mathrm{l}$. As shown in Figure 1, none of the control sera gave a signal above the $99^{\text {th }}$ percentile, which was taken as cutoff to define antibody positivity.

The prevalence of IAA and PAA was determined in sera of patients and relatives (Fig. 2). The overall prevalence of PAA in patients was $34.0 \%$ vs $22.7 \%$ for IAA $(p<0.05)$. This difference was present in both ICA-positive (PAA 36\%, IAA 24\%) and ICA-negative (PAA $29 \%$, IAA $19 \%$ ) patients. A higher prevalence of PAA was also seen in ICA-positive relatives ( $44 \%$ vs $31 \%$ ), but the difference was not significant because of the limited number of probands. In ICA-negative relatives we found a low prevalence $(0.9 \%)$ for both antibodies. There was no correlation between individual ICA-titres and strength of (pro-)insulin binding in any of the groups investigated $(r=0.19$ or $0.21, p>0.05)$. Of the 16 ICA-positive relatives six developed diabetes within 2-4 years of follow-up (mean 3.2 years). Among these two were IAA-positive and four PAA-positive. Of the 10 non-diabetic individuals (mean follow-up 3.0 years) three had PAA and three IAA. The positive predictive value for a PAA-positive test in an ICA-positive individual was determined as $57 \%$ vs $40 \%$ for IAA.

IAA and PAA results were correlated at the level of individual sera (Fig. 3). Most sera positive for IAA also contained PAA and vice versa. There was a close correlation between IAA and PAA in the amount of ligand bound per 1 of serum $(r=0.95, p<0.01 ; y=0.817 \times$ +1.593 ). A small number of sera gave much stronger signals with proinsulin than with insulin, the reverse was true for one serum.

The crossreactivity of IAA and PAA was further analysed by competition of either labelled insulin or pro- 
A

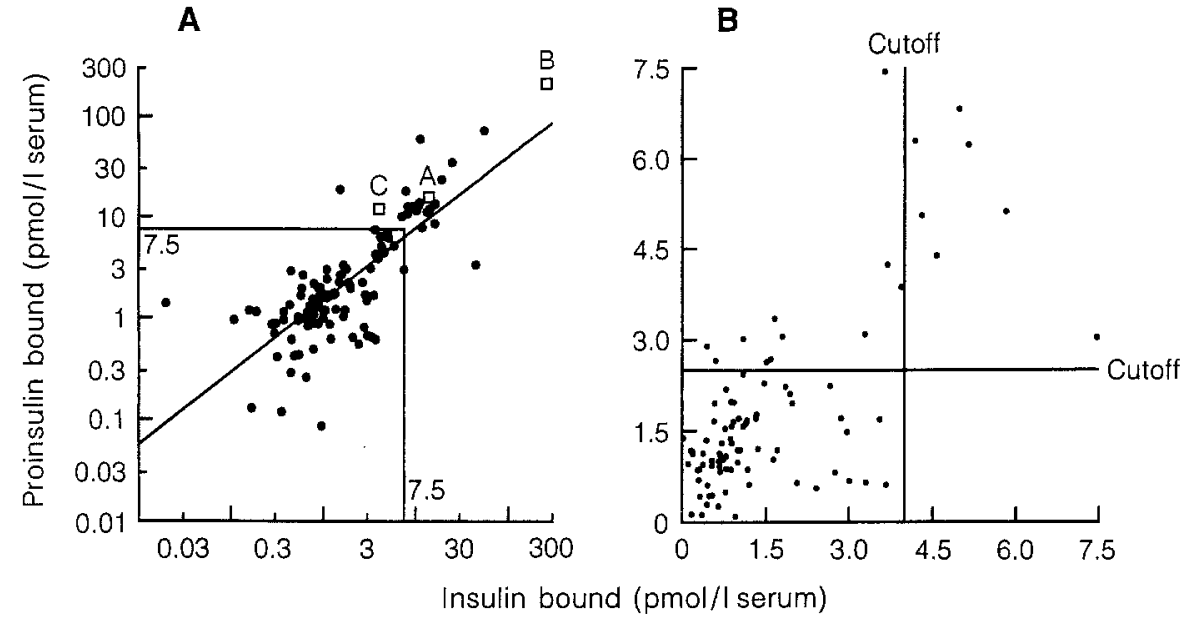

Fig.3 A, B. Correlation of insulin and proinsulin binding in individual sera. A All sera except islet cell antibody-negative relatives and control sera. Log-scaling. Serum A, B and C of Figure 4 to 6 have been marked $(\square)$. B Sera below 7.5 pmol antigen binding/l. Each dot represents a single serum, the regression line is shown in $\mathbf{A}$, the cutoff in B

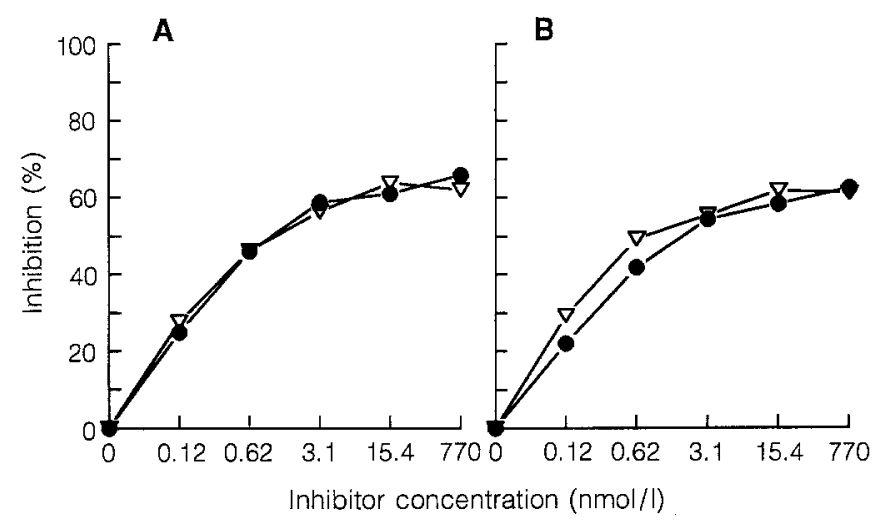

Fig. 4A, B. Equal crossreactivity of insulin autoantibodies (IAA) and proinsulin autoantibodies (PAA). A Serum A was mixed with ${ }^{125}$ I-proinsulin in the presence of increasing amounts of inhibitor. B The same serum was mixed with ${ }^{125} \mathrm{I}$-insulin in the presence of increasing amounts of inhibitor. Proinsulin as inhibitor $\mathbf{0}$; Insulin as inhibitor $\triangle$

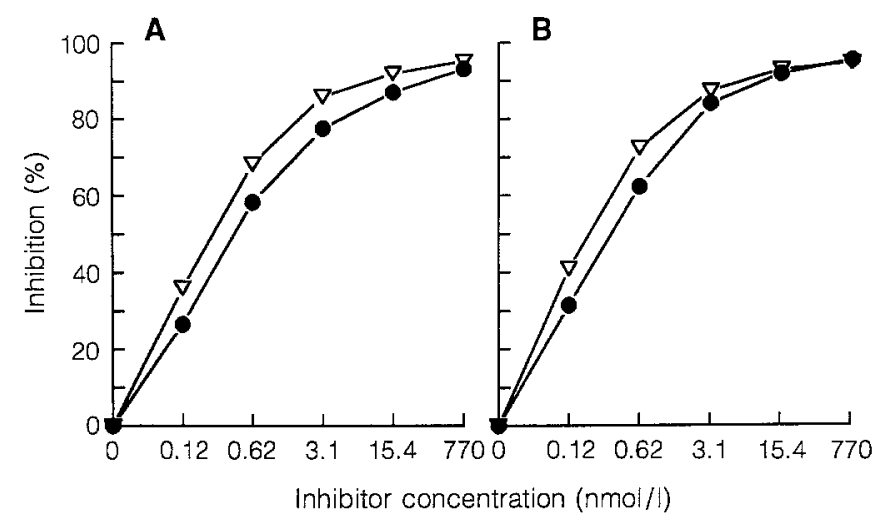

Fig.5 A, B. Higher avidity of an insulin autoantibody (IAA)and proinsulin autoantibody (PAA)-positive serum to insulin. A Serum B was mixed with ${ }^{125}$ I-proinsulin in the presence of increasing amounts of inhibitor. B The same serum was mixed with ${ }^{125} \mathrm{I}$-insulin in the presence of increasing amounts of inhibitor. Proinsulin as inhibitor $\bullet$;nsulin as inhibitor $\triangle$

insulin with both peptides. Three sera were analysed, one (A) with equal binding of insulin and proinsulin, the others preferentially binding insulin (B) or proinsulin (C). As shown in Figure 4 serum $A$ contains antibodies with equal avidity towards the two antigens, regardless of whether insulin or proinsulin was used as radiolabelled ligand. Serum B revealed a slight but significant $(p<0.05)$ higher avidity towards insulin with both insulin and proinsulin as radiolabelled ligand (Fig.5).

Serum C contains antibodies crossreacting with insulin and proinsulin (Fig. 6A) plus an antibody population monospecific for non-insulin determinants of proinsulin (Fig. 6B). These antibodies reacted only minimally with C-peptide (Fig, 6C). Tested directly by using ${ }^{125} \mathrm{I}$-tyrhuman C-peptide this serum was revealed to be C-peptide antibody negative (data not shown).

\section{Discussion}

The data presented show that antibodies binding to proinsulin are more frequent in newly diagnosed Type 1 diabetic patients and persons at risk than IAA, but have the same low prevalence in probands with a well-defined, low risk for Type 1 diabetes (i.e. ICA-negative first degree relatives [9]). Following standard immunological practice we considered as PAA all antibodies to proinsulin (against $\mathrm{A}, \mathrm{B}$ and $\mathrm{C}$ chain determinants and epitopes lost during split of proinsulin) therefore including that population of IAA which also binds proinsulin. Although sensitivity and specificity of a PAA- or IAAdetermination cannot be given for the whole family study population, because we did not follow-up the ICA-negative individuals, the predictive value of the autoantibodies was determined in ICA-positive first degree relatives and was found to be $57 \%$ for PAA and $40 \%$ for IAA.

In a recent abstract, Castano et al. [10] also reported an increased prevalence of PAA (as defined here) compared to IAA when studying 50 sera from first-degree relatives of Type 1 diabetic patients, which is in good concordance with our findings.

In performing this study we were aware of the results of the Fourth International Workshop on the Standardization of IAA showing that fluid phase radioimmunoassays and solid phase assays (ELISA) detect different IAA populations which overlap only partially, and that radioimmunoassay-determined IAA are much more closely associated with Type 1 diabetes [3]. We therefore 


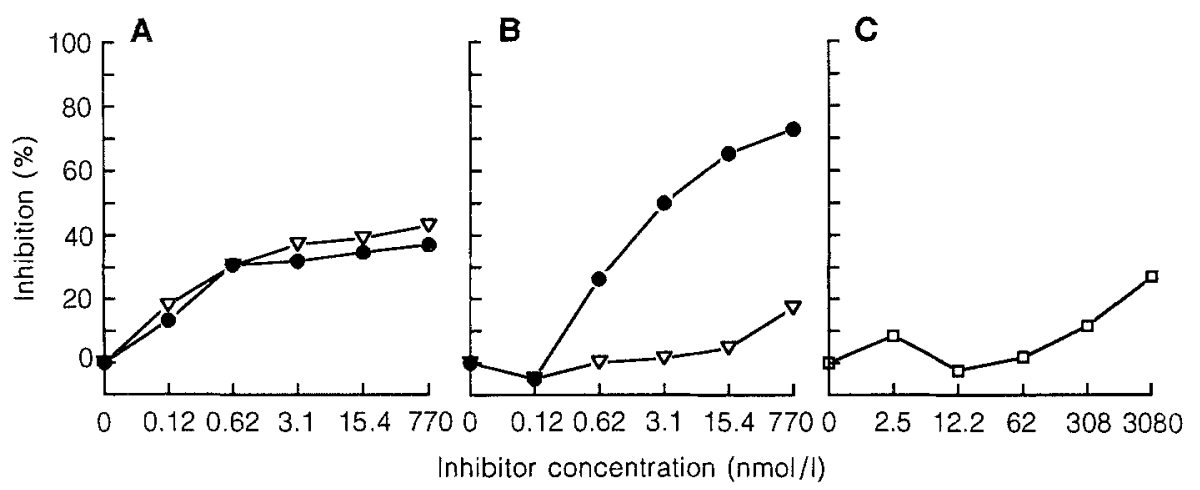

Fig. 6A-C. Higher avidity of an insulin autoantibody (IAA)- and proinsulin autoantibody (PAA)-positive serum to proinsulin. A Serum C was mixed with ${ }^{1.25}$ I-insulin in the presence of increasing amounts of insulin or proinsulin. B The same serum was mixed with ${ }^{125}$ I-proinsulin in the presence of increasing amounts of insulin or proinsulin. C The serum was mixed with ${ }^{125} \mathrm{I}$ proinsulin in presence of increasing amounts of C-peptide. Proinsulin as inhibitor ; Insulin as inhibitor $\triangle ; C$-peptide as inhibitor

used the same RIA protocol for the determination of IAA and PAA with equimolar concentrations of insulin and proinsulin in the reaction mixture.

The superior results obtained with proinsulin as tracer were the consequence of two different effects. Firstly, it detected an additional population of autoantibodies, directed against the $\mathrm{C}$-chain and the adjacent amino-acids lost during the cleavage of proinsulin into insulin and $\mathrm{C}$ peptide. One such example is presented in Figure 6, where the antibody reactivity to proinsulin was only partially inhibited by insulin and only minimally by C-peptide, leaving proinsulin as the only potent inhibitor. Proinsulin specific epitopes, in particular the split positions of the proinsulin molecule, should be taken into consideration for locating the determinants of such "proinsulin" autoantibodies. It is interesting that none of the IAA-positive sera turned negative when probed with proinsulin. This indicates that few IAA are directed against insulin determinants which are not accessible in the precursor molecule proinsulin. One possible explanation is that proinsulin rather than insulin is the immunogen giving rise to both IAA and PAA. Proinsulin is secreted physiologically by Beta cells in small amounts [11] and some preliminary evidence links elevated serum proinsulin levels with Betacell dysfunction $[11,12]$ and the genetic predisposition for Type 1 diabetes [14], although the latter has been disputed [15].

The second reason why proinsulin as a tracer is superior to insulin in detecting diabetes-associated antibodies is the lower signal found with normal sera. As a consequence, the 4 SD cutoff limit is lower for PAA than for IAA. Hence, a lower level of antigen binding is required to identify PAA than IAA. This allows the detection of additional low titre PAA-positive sera. It should be stressed that the findings described here apply only to radioimmunoassay-determined proinsulin autoantibodies, which apparently constitute the high affinity portion of all proinsulin binding immunoglobulin, whereas the ELISA also detects low affinity antibody populations [16]. However, when searching for PAA with ELISA we also found that a higher number of patient sera reacted with proinsulin than with insulin [2].

In summary, we found a higher prevalence of PAA in newly diagnosed Type 1 diabetic patients and persons at risk for developing Type 1 diabetes. Further studies should determine the prevalence of PAA in other autoimmune diseases and their natural course prior to diabetes onset in order to assess their value for the prediction of Type 1 diabetes.

Acknowledgements. The expert technical assistance of Ms. K. Isselmann is gratefully acknowledged. This work was supported by the Ministerium für Wissenschaft und Forschung des Landes Nordrhein-Westfalen and the Bundesministerium für Jugend, Familie, Frauen und Gesundheit.

\section{References}

1. Palmer JP, Asplin C, Clemons P et al. (1983) Insulin antibodies in insulin-dependent diabetes before insulin treatment. Science 222: $1337-1339$

2. Kuglin B, Gries FA, Kolb H (1988) Evidence of IgG autoantibodies against human proinsulin in patients with IDDM before insulin treatment. Diabetes 37: 130-132

3. Kuglin B, Kolb H, Greenbaum C, MacLaren NK, Lernmark $\AA$, Palmer JP (1990) The Fourth International Workshop on the Standardisation of Insulin Autoantibody Measurement. Diabetolgia 33: 638-639

4. Diabetes mellitus (1985) Report of a WHO Study group, Technical Report Series 727 WHO, Geneva 1985

5. Kuglin B, Bertrams J, Linke C, Gries FA, Kolb H (1989) Prevalence of cytoplasmic islet cell antibodies and insulin autoantibodies is increased in subjects with genetically defined high risk for insulin-dependent diabetes mellitus. Klin Wochenschr 67: 66-73

6. Kolb H, Dannehl K, Grüneklee D et al. (1988) Prospective analysis of islet cell antibodies in children with Type 1 (insulindependent) diabetes mellitus. Diabetologia 31: 189-194

7. Bonifacio E, Boitard C, Gleichmann H, Shattock MA, Molenaar JL, Bottazzo GF (1990) Assessment of precision, concordance, specificity and sensitivity of islet cell antibody measurement in 41 assays. Diabetologia 33: 731-736

8. Dixon K (1974) Measurement of antibodies to insulin in serum. Clin Chem 20: 1275-1281

9. Bonifacio E, Bingley PJ, Shattock M et al. (1990) Quantification of islet-cell antibodies and prediction of insulin-dependent diabetes. Lancet I: 147-149

10. Castano L, Ziegler R, Reske I, Eisenbarth GS (1990) Proinsulin autoantibodies (PIAA) in prediabetics and autoantibody positive relatives of patients with Type I diabetes. Diabetes 39: 247 (Abstract)

11. Heding LG, Ludvigsson J, Kasperska-Czyzykowa T (1981) ß-cell secretion in non-diabetics and insulin-dependent diabetics. Acta Med Scand [Supp]] 656:5-9

12. Ward WK, LaCava EC, Paquette TL, Beard JC, Wallum BJ, Porte Jr D (1987) Disproportionate elevation of immunoreactive proinsulin in Type 2 (non-insulin-dependent) diabetes mellitus and in experimental insulin resistance. Diabetologia 30:698702 
13. Hartling SG, Lindgren F, Dahlquist G, Persson B, Binder Ch (1989) Elevated proinsulin in healthy siblings of IDDM patients independent of HLA identity. Diabetes 38: 1271-1274

14. Heaton DA, Millward BA, Gray IP, Hales CN, Pyke DA, Leslie RDG (1988) Increased proinsulin levels as an early indicator of B-cell dysfunction in non-diabetic twins of Type 1 (insulin-dependent) diabetic patients. Diabetologia 31: 182-184

15. Knip M, Hartling SG, Karjalainen J, Penttilä P, Binder C, Åkerblom HK (1990) Proinsulin concentrations in children with newly diagnosed Type 1 (insulin-dependent) diabetes and in their siblings. Diabetologia 33: A 68 (Abstract)

16. Sodoyez-Goffaux F, Koch M, Dozio N, Brandenburg D, Sodoyez $\mathrm{J}-\mathrm{C}$ (1988) Advantages and pitfalls of radioimmune and enzyme linked immunosorbent assays of insulin antibodies. Diabetologia 31: $694-702$

Received: 25 April 1991

and in revised form: 27 August 1991

Dr. K.P.Böhmer

Diabetes Research Institute

University of Düsseldorf

Auf'm Hennekamp 65

W-4000 Düsseldorf 1

FRG 